\title{
L'industrie pharmaceutique s'engage à livrer les principes actifs aux pharmacies
}

Hanspeter Kuhn

Avocat, responsable du Service juridique, secrétaire général adjoint de la FMH

Correspondance: FMH / Domaine Produits thérapeutiques Elfenstrasse 18

Case postale 300 3000 Berne 15

Tél. 0313591111

Fax 0313591112
Comme annoncé par H+ dans son eFlash du 17 octobre 2013, les associations de l'industrie pharmaceutique suisse «encouragent leurs membres à livrer aux pharmacies des hôpitaux, aux pharmacies d'officine et aux médecins les principes actifs nécessaires pour des formulations médicales particulières. Elles ont confirmé cette volonté dans une déclaration d'intention à l'endroit des fournisseurs de prestations.»

«Pour les enfants, les patients âgés ou les personnes souffrant d'affections particulières, par exemple de troubles de la déglutition, des médicaments ne sont souvent pas disponibles dans les dosages ou les formes galéniques adaptées. En effet, il n'est pas rentable pour l'industrie pharmaceutique de proposer des produits spécifiques pour des groupes de patients parti- culiers et peu nombreux. Les pharmacies des hôpitaux sont donc souvent amenées à produire elles-mêmes des dosages particuliers à partir de médicaments acquis sur le marché ou de leurs principes actifs. Jusqu'à présent, la question se posait de savoir si, et jusqu'à quel point, une telle manière de faire était autorisée pour les médicaments protégés par un brevet.

Les associations de l'industrie pharmaceutique suisse s'engagent maintenant dans une déclaration d'intention envers les fournisseurs de prestations à soutenir cette manière de procéder lorsque des produits finis correspondants ne sont pas disponibles.»

Cela permettra de garantir à l'avenir également que les dosages et les formes galéniques spécifiques prescrits par les médecins à des groupes de patients particuliers puissent être produits.

\section{Pour anticiper les défis. La statistique médicale de la FMH.}

\section{Déclarez vos données.}
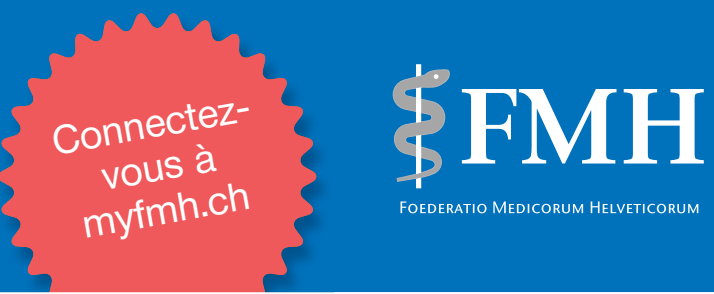